\section{Engaging Auditory Modalities through the Use of Music in Information Literacy Instruction}

\author{
Katherine Kimball and \\ Lisa O'Connor, \\ Columnists
}

Correspondence concerning this column should be addressed to Lisa

O'Connor, Assistant Professor, School of Library and Information Science, University of Kentucky, Lexington, $K Y$ 40506.

\author{
Lisa O'Connor is an Assistant \\ Professor in the School of Library \\ and Information Science at the \\ University of Kentucky in Lexington, \\ and Katherine Kimball is a graduate \\ student enrolled in the School.
}

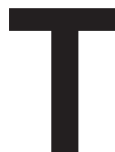

he human body is composed of multiple sensory modalities, and each of them engages a different part of the brain when stimulated. A common assumption of learning theory is that individuals prefer some sensory paths over others for learning, hence the distinction between kinesthetic, verbal, visual, and aural learners. ${ }^{1}$ Multiple intelligences and learning style theory suggest that teachers engage the widest variety of learners in the classroom by offering differentiated instruction using multiple sensory cues. Research also suggests that all learners benefit from multiple sensory stimuli in learning regardless of their learning preferences because the brain operates at its best in complex environments. We know the brain is "designed" to process many inputs at once-in fact, it actually prefers it so much, a slower linear pace actually reduces understanding. ${ }^{2}$ Thus a differentiated learning environment that activates multiple sensory paths not only accommodates the particular learning preferences of individuals, it also enhances learning for everyone.

Aural learners prefer learning through hearing. They are particularly receptive to auditory stimuli that involve tone, rhythm, and pitch. Recommendations for providing aural stimuli in the classroom often have been confined to using music as a memorization device (singing the alphabet, for example) or playing background music to enhance the general learning environment. This article will suggest more meaningful ways to use music to teach information literacy (IL) skills and demonstrate that incorporating music is an excellent means for adding interest, variability, and inquiry learning into IL instruction.

\section{EXTENDING CLASSROOM LEARNING WITH MUSIC}

Because of the constraints on information professionals' access to learners, IL instruction often occurs in brief, standalone sessions, sometimes called "one-shots" in the literature. ${ }^{3}$ The one-shot instructional session is a convenient format conducive to the thinly stretched schedules of professors, librarians, and students; however, it has several drawbacks. Incorporating music into IL instruction may ameliorate some of those drawbacks by providing a creative and efficient means for stimulating an additional sensory path to engage the brain in learning.

The first drawback of the one-shot session is time. The traditional fifty to seventy-five minutes allotted for instruction is hardly conducive to achieving complex IL learning outcomes. Kenny calls the one-shot a "trailer for the full-length 
feature ... the ultimate goal for a one-shot ... session is to have students actively engage with the librarians and library resources to provide a glimpse into the many ways the library supports student learning." ${ }^{\prime 4}$ Librarians often find their teaching methods constrained by time and struggle to address IL beyond the skills-building level of training. A common cultural construct, such as music, is useful in providing starting points for analogy and metaphor building, which increases conceptual learning.

While neither the instructor nor the students may have formally studied music, human beings are inherently musical. Studies have shown that rhythmic intelligence is the first of the intelligences to develop: The rhythm of the maternal heart beat and other external sounds, such as music, penetrate the womb and stimulate fetal response. ${ }^{5}$ By the age of one, children of all cultural backgrounds engage in spontaneous singing (prior even to attaining language), and by age five they are already familiar with musical patterns and recognize when unexpected musical events occur. ${ }^{6}$ Most students, even international students, have grown up surrounded by examples of Western music, from "Happy Birthday" to the international reach of pop music to the near-ubiquitous Christmas carols. By making connections to music, a subject with which students are already familiar, librarians help students extend their knowledge base more expediently. Alternating between discussions of the abstract concepts (illustrated with musical examples) and concrete applications (e.g., a demonstration of database searching on a topic of interest) enables an efficient, but more conceptually complex, treatment of IL content.

The second problem of the one-shot instructional session is retention and recall. When students are bombarded with information during a brief amount of time-particularly through a single medium, such as lecture-their retention is understandably low. The link between music and memory enhancement is clear. It is astonishing how well people remember songs from the distant past in contrast to people's retention of other types of information. Alzheimer's research provides evidence of the music's powerful connection to the brain. ${ }^{7}$ Even severely demented patients have a positive response to familiar tunes, indicating that musical memory is deeply rooted. Memory appears to be enhanced by music because it involves the whole brain; when engaged with a song, the left brain (which handles language, logic, mathematics, etc.) processes the lyrics, while the right brain (which handles rhythm, rhyme, pictures, emotions, etc.) processes the music. This is particularly useful for college students, who are accustomed to interacting with information in multiple formats and through a variety of simultaneous stimuli. ${ }^{8}$

\section{ADDRESSING INFORMATION LITERACY STANDARDS THROUGH MUSIC}

The Association of College and Research Libraries'(ACRL) Information Literacy Competency Standards for Higher Education provide the framework for IL instruction in most academic libraries. ${ }^{9}$ These standards provide a natural framework for designing IL instruction. What follows will demonstrate how music can be used to teach the core IL competencies described in the ACRL standards typically addressed by librarians.

The first standard asks that the student know that there is an information need and to determine its extent. Concepts that are included under this heading include the ability to distinguish between primary and secondary sources, to understand the potential audience of an information source, and the ability to reevaluate the information need.

One set of musical examples to illustrate the difference between primary and secondary sources is to contrast two recordings of Handel's "Music for the Royal Fireworks." Originally written for an assortment of winds and percussion to achieve a military sound ( 24 oboes, 12 bassoons, 9 trumpets, 9 horns, and 3 timpani), today it is most frequently played as a work for the modern orchestra. Most students will have a strong preference for one recording over the other; presumably they will be more comfortable listening to the sounds that are more familiar. While the recordings are being played, the instructor might require the students write a few words or a one-minute paper describing each piece. The answers could be tallied on the board and a consensus reached. Then the instructor could provide some background about the two works and their instrumentation and compare them to information sources. Once the instructor shifts the focus from which piece the students prefer hearing to which one represents a historically accurate performance, the results should swing from one to the other.

The second ACRL IL competency standard requires students to use information retrieval systems effectively. To achieve this goal, students must formulate a search strategy, understand subject-specific and controlled vocabulary, and perform a search across multiple interfaces.

The use of controlled vocabulary can be highlighted by contrasting two works of Western classical music. A Mozart symphony will have a very different vocabulary than a work by the serialist composer Anton Webern. In some compositions, Webern used matrices and mathematical models to determine pitch sequences. This freed him from tonality, the familiar concept of using scales and harmony to determine pitch sequences. Research indicates that at age five, the human brain has a natural understanding of harmonic progression in the same way that an implicit understanding of language has already been formed. ${ }^{10}$ Webern's serial compositions, constructed almost randomly, are devoid of the harmonic meaning normally found in Western classical music.

Listening to Webern is an intellectual exercise, while listening to Mozart is almost effortless by comparison. Webern and Mozart are using the same pitches, rhythms, and musical forms, but Mozart applies a harmonic structure that is easy to understand. In this example, Mozart is using a harmonic controlled vocabulary, one that students will instinctively recognize.

The third standard asks the student to evaluate sources and select information to add to their own knowledge base. 


\section{INFORMATION LITERACY AND INSTRUCTION}

Concepts addressed by this standard include synthesis, authority, the role of cultural context, the recognition of prejudice, and the ability to compare sources.

This standard lends itself to multiple musical examples. The comparison of sources could be illustrated by comparing two recordings of the same work, preferably one that is well known. For example, a recording of a professional orchestra playing the opening of Beethoven's Fifth Symphony could be contrasted with a recording of a high school orchestra found on YouTube, or a recording of a well-known song could be contrasted with a cover by an amateur group. The students should be able to immediately perceive two things: the ensembles are playing the same piece, and the quality of the performances is dramatically different. In addition to listing words that would describe each performance, they could also be prompted to write a one-minute paper or other descriptive statement outlining the differences between either the two recordings or between the professional and high school orchestras. For example, professional orchestras charge an admission fee, which is absent from most high school concerts. This could be paired with an exercise in which students are given two articles on the same topic, one from a library database and the other from the Web. Hopefully, after contrasting the musical examples, students will be more attuned to possible variations in quality between information resources.

Another musical illustration from the third standard involves a cultural comparison. Two musical works that are from different genres but deal with the same topic could be played. For example, an excerpt of a movement from Berlioz's "Symphonie Fantastique" could be paired with the Beatles' "Lucy in the Sky with Diamonds." The principal theme of "Symphonie Fantastique" allegedly came to Berlioz during an opium-induced dream, and would be more representative of drug use during the nineteenth century.

Students might be asked to write down some thoughts as the examples are being played; the teacher can then collect these impressions. This would work especially well in a psychology or social work class in which a student was writing a paper about drug use. After the instructor provides background information for each piece, the students could be asked to listen to the examples again and answer some leading questions in small groups. For example, the students could be asked which composition they felt was more representative of a particular time period, or if they felt one conveyed the concept of drug use better than the other. This would require students to confront their first conception (most likely that the pieces had nothing to do with one another).

The fifth standard requires that students grasp the implications of information use, including any legal and ethical issues. Other concepts included under this standard are plagiarism, intellectual property, copyright, and the difference between free and fee-based resources.

The issues of plagiarism, copyright, and intellectual property could be discussed using any rap or hip-hop song that includes samples of other songs. ${ }^{11}$ This example could be contrasted with a "mash-up," in which two or more songs are combined without any new input. For example, Kanye West's "Gold Digger" uses a sample from Jamie Foxx's interpretation of the Ray Charles song "I've Got a Woman." The sample sets the tone for the song and provides some of the lyric underpinnings, but West is clearly the author of the song. This could be contrasted with a mash-up in which "Gold Digger" and Walter Murphy's "Fifth of Beethoven" are combined. Though clever, this mash-up is not a new creative work.

The difference between using excerpts to reinforce your arguments (sampling) and co-opting others' work (blending two songs into a mash-up) should be clear to students. While the musical examples are being played, students could record their observations and then discuss them in small groups. Starting with a musical form that most students are familiar with to teach a complex issue like copyright helps students extend their knowledge.

One problem with the use of mash-ups as musical examples is that some are much more complex than others. For example, Danger Mouse's mash-up of the Beatles' "White Album" and Jay-Z's "Black Album" to create the "Grey Album" involves a reimagining of the source material. It could be argued that this represents an original creative work authored by Danger Mouse. This example would be an excellent vehicle to discuss copyright law: Danger Mouse was threatened with legal action by several parties for breach of copyright. The ambiguity of this case also lends itself to the sometimes messy problems of information use, and as Hensley points out, "educators need to teach through the weaknesses and problems of information use, not through perfect models that exclude them." 12

Although the use of music to teach IL is generally an effective strategy, it should be noted that a small percentage of the population have musical-perception disorders. This can range from synesthesia (the experiencing of multiple senses at the same time, including music and color or taste) to what Peretz has described as "congenital amusia." ${ }^{13}$ Peretz estimates that 4 percent of the general population are born with an inability to distinguish the relationships between pitches that are so important to music perception; pitch variation in normal speech is much less subtle than the difference in pitch between scale degrees in Western music. People suffering from this condition are frequently unable to recognize wellknown songs without reading the lyrics and do not react to unexpected musical events. ${ }^{14}$

Instructors run the risk of failing to connect with students in this population when using musical examples. A similar scenario exists with visual examples and colorblind populations. Incorporating visual examples that reflect the content of the musical examples (and even switching them so that one is shown while the other example is playing) could enhance the content for nonmusical learners. The use of music would also enhance the content of visual examples for colorblind individuals. 


\section{CONCLUSION}

Students' familiarity with the basic grammar and syntax of Western music provides an excellent means of setting up problem-based learning. The distinctions between musical examples used in class should be clear enough to provide the foundation for a discussion by as many students as possible, whether or not they have a musical background. Chosen carefully, musical examples can also improve instruction because listening to music activates different parts of the brain that are not involved in language processing, especially when the listener encounters something unexpected. Adding music to IL instruction is an excellent means for maximizing instructional time, deepening the conceptual complexity of IL instruction and increasing students' retention and recall. It is an excellent way to expand the pedagogical repertoire of instructional librarians across educational settings.

\section{References}

1. David C. Leonard, Learning Theories: A to Z (Westport, Conn.: Greenwood, 2002).

2. Eric Jensen, The Learning Brain (Switzerland: The Brain Store, 1994).

3. Barbara F. Kenney, "Revitalizing the One-Shot Instruction Session
Using Problem-Based Learning," Reference \& User Services Quarterly 47, no. 4 (2008): 386-91.

4. Ibid., 387.

5. Isabelle Peretz, "The Nature of Music from a Biological Perspective," Cognition 100, no. 1 (2006): 1-32.

6. Isabelle Peretz, "Musical Disorders: From Behavior to Genes," Current Directions in Psychological Science 17, no. 5 (2008): 329-33.

7. Naomi Ziv et al., "The Effect of Background Stimulative Music on Behavior in Alzheimer's Patients," Journal of Music Therapy 44, no. 4 (2007): 329-43.

8. Carolyn N. Willis and William Joseph Thomas, "Students as Audience: Identity and Information Literacy," portal: Libraries and the Academy 6, no. 4 (2006): 431-34.

9. Association of College and Research Libraries, "Information Literacy Competency Standards for Higher Education," www.ala.org/ ala/mgrps/divs/acrl/standards/ informationliteracycompetency.cfm (accessed Aug. 28, 2008).

10. Isabelle Peretz and R. J. Zatorre, "Brain Organization for Music Processing," Annual Review of Psychology 56 (2005): 89-114.

11. Sarah R. Wakefield, "Using Music Sampling to Teach Research Skills," Teaching English in the Two-Year College 33, no. 4 (2006): 357-60.

12. Randy B. Hensley, "Information Literacy and Instruction: Curiosity and Creativity as Attributes of Information Literacy," Reference \& User Services Quarterly 44, no. 1 (2004): 32.

13. Peretz, "Musical Disorders," 329.

14. Ibid. 